\title{
The impact of infection and nutrition on gut function and growth in childhood
}

\author{
Peter G. Lunn \\ Medical Research Council, Keneba, The Gambia
}

\begin{abstract}
Poor growth performance during infancy and early childhood is a frequent fact of life in most developing countries. Work in The Gambia has demonstrated that more than $43 \%$ of observed growth faltering during the first 15 months of life can be explained by the presence of a mucosal enteropathy in the small intestine. Within communities the illness is very common: in the area investigated more than $95 \%$ of infants above 8 months of age were affected, and on average they suffered a growth-limiting enteropathy for more than $75 \%$ of their first year of life. Two mechanisms of weight loss have been defined. First, partial villus atrophy reduces absorption and digestion of lactose and probably other nutrients. Second, and more importantly, damage to the mucosal barrier allows translocation of macromolecules into the mucosa and blood, triggering both local and systemic immune and inflammatory mechanisms. Given the severity of the enteropathy it is not surprising that infants fail to grow at a normal rate. Recent findings suggest that these lesions continue throughout childhood and into adulthood. Thus, a persistence of chronic, local and systemic inflammation throughout childhood may be responsible for continued poor growth during this period. Although the nature of the enteropathy and the mechanisms of growth failure have been defined, the factors involved in the initiation and persistence of the intestinal lesion remain uncertain, making clinical management difficult. More work is clearly required to elucidate these factors and to define interventions to prevent or treat the enteropathy.
\end{abstract}

Malnutrition: Gastrointestinal enteropathy: Intestine:

Infants: Translocation

In most developing countries growth of infants and young children is much poorer than expected. This is certainly the case in the rural West Kiang region of The Gambia, the site at which most of the studies to be described have been carried out. During the first 3 months of life (Fig. 1) mean weights and lengths of infants are only slightly below the National Center for Health Statistics (Hamill et al. 1979) standards, and there is some evidence of catch-up growth from a rather low birth weight. Beyond this time, however, growth faltering occurs, and there is a progressive fall in $\mathrm{Z}$-scores with age so that by 14 months mean Z-scores for weight- and length-for-age have fallen to $-2 \cdot 03$ and $-2 \cdot 13$ respectively (Lunn et al. 1991a,b). Extensive investigations over many years have indicated that although the infants' diet can be described as marginal in adequacy, neither the quality nor the quantity consumed can explain such poor growth performance (Prentice, 1993). Children in this area of The Gambia receive substantial amounts of breast milk well into the second year of life, and both macro- and micro-nutrient supplement trials have failed to improve the growth pattern.

On the other hand, early data indicated that growth failure was associated with the frequent and often persistent episodes of diarrhoeal disease suffered by the children (Cole \& Parkin, 1977). Although there is no doubt that diarrhoeal episodes are associated with acute weight loss, data from many parts of the developing world suggest that this illness is not responsible for the long-term pattern of growth retardation described (Briend et al. 1989). Using a strict criterion for identifying diarrhoea (i.e. three or more loose stools per d), it is clear that in The Gambia there is also no relationship between diarrhoeal disease and growth. In marked contrast to this finding, however, our investigations have shown that there is a very high prevalence of gastrointestinal (small intestinal) disease, which may or may not be associated with diarrhoea, and that this factor is a major determinant of the poor growth of these infants (Lunn et al. 1991a). It is important to appreciate that in this instance

Abbreviation: Ig, immunoglobulin.

Corresponding author: Dr Peter G. Lunn, present address 21 Cowslip Drive, Little Thetford, Ely, Cambs. CB6 3JD, fax +44 (0) 1223 426617, email Peter.Lunn1@tesco.net 


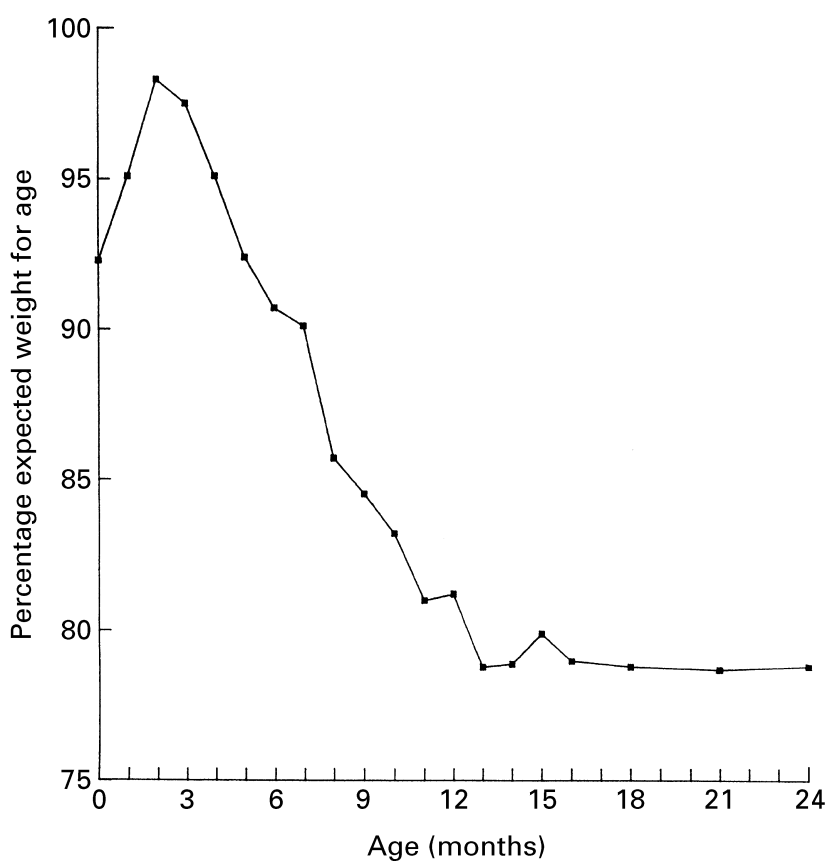

Fig. 1. Growth performance of Gambian infants expressed as percentage of expected weight-for-age according to National Center for Health Statistics (Hamill et al. 1979) standards.

diarrhoea cannot be equated with gastrointestinal disease (Lunn et al. 1993).

Gambian children admitted to hospital with severe malnutrition and a history of persistent diarrhoea have been found to have a grossly abnormal small intestinal mucosa (Sullivan et al. 1991). All children had partial villus atrophy, and in the more extreme cases a flat coeliac-like mucosa heavily infiltrated with intra-epithelial lymphocytes was observed (for further details of the pathology, see p. 150). We and others have found that this type of mucosal damage can be assessed using the lactulose-mannitol intestinal permeability test, and have used this technique to make repeated assessments of the small intestinal status of apparently-'normal' Gambian village infants.

The dual sugar (lactulose-mannitol) intestinal permeability test is a non-invasive technique that provides information about some aspects of the function and integrity of the small bowel mucosa (Menzies, 1984). Subjects are given an accurately measured small oral dose of the two probes, lactulose and mannitol, dissolved in water. All urine passed over the next $5 \mathrm{~h}$ is collected (infants are fitted with a urine bag), the volume measured, and a portion taken for sugar analysis. During the test subjects are encouraged to drink water, but food is withheld for at least $2 \mathrm{~h}$. Intestinal permeability (expressed as urinary lactulose:mannitol) is calculated as urinary lactulose concentration divided by urinary mannitol concentration. In addition, the percentage recoveries of the two sugars in the urine can be calculated. The theory of the test is that mannitol, a monosaccharide, is passively absorbed across the mucosa, and thus gives an indication of the absorptive surface area of the small intestine, i.e. mannitol uptake is reduced in villus atrophy. Lactulose, a disaccharide, cannot be taken up by healthy enterocytes, and in a normal small intestine only small amounts are absorbed, probably via paracellular routes. However, where the mucosa is damaged, larger amounts of lactulose cross the intestinal barrier into the blood, so lactulose uptake can be regarded as an index of leakiness (Ford et al. 1985). Within the body both probes remain intact, they remain in the extracellular fluid compartment and both are rapidly excreted by the kidneys (Elia et al. 1987). Consequently, the amounts found in the urine reflect the amounts taken up by the two different routes in the small intestine.

Intestinal permeability of Gambian infants increases with age throughout the first year of life (Lunn et al. 1991b). At 3 months of age values in UK infants are similar to those found in their Gambian counterparts. However, beyond this age the groups diverge, permeability in UK children falling towards adult levels by the end of the first year of life, whilst Gambian values reach a peak at this time when they are about 5-fold greater than UK levels. Almost all Gambian children show some period of abnormality during the first year of life. The prevalence of Gambian infants with an elevated intestinal permeability (compared with UK values) is about $50 \%$ at 5-6 months, rising to $96 \%$ above 10 months. The increased lactulose:mannitol value is due to both decreased mannitol and increased lactulose uptake, i.e. deterioration in absorptive surface area and increased leakiness. The rise in intestinal permeability clearly coincides with the fall in growth performance, and regression analysis of the data revealed there was indeed an association between the two variables. Close relationships between intestinal permeability and length and weight growth can be demonstrated, both short- and long-term, and within and between individuals. In fact, mean permeability values taken over an average 9-month period of study was able to predict more than $43 \%$ of length growth and $40 \%$ of weight growth over this period (Lunn et al. 1991a). Fig. 2 shows the close 'mirror image' association between intestinal

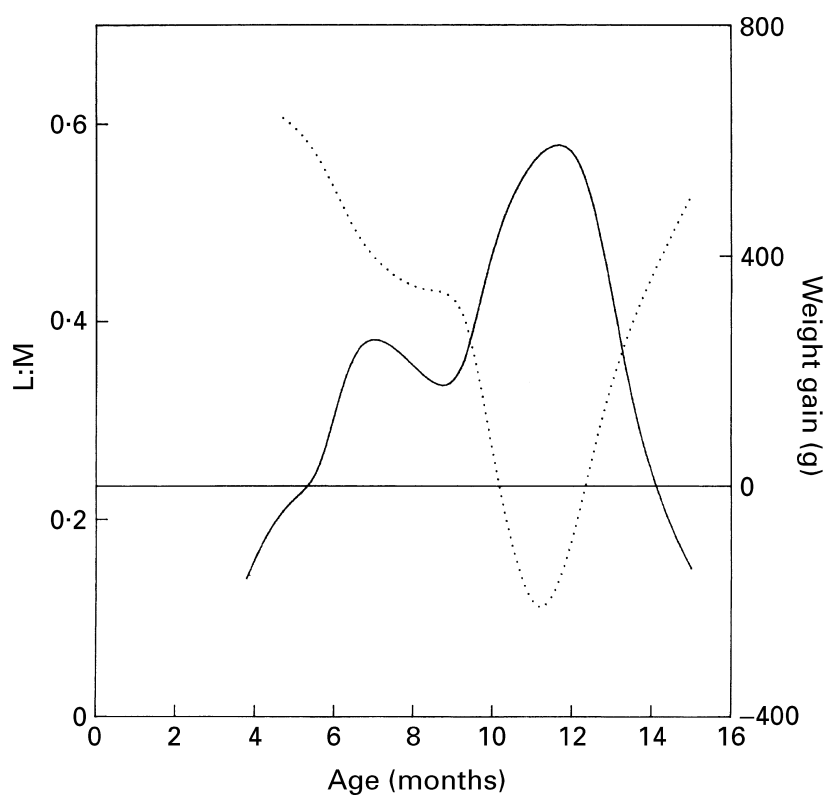

Fig. 2. 'Mirror image' relationship between growth (g/month; $\cdots$.) and intestinal permeability assessed by the dual-sugar (lactulose : mannitol; L:M; -) test in two typical Gambian children. 
permeability and weight growth observed in Gambian infants.

If the permeability ratio is split into its two components, i.e. the percentage recoveries of lactulose and mannitol in the urine, statistical analysis suggests that $40-45 \%$ of growth faltering is related to reduced mannitol uptake, but that the larger part, 55-60 \% of predicted growth, is associated with increased lactulose uptake. Moreover, these associations with growth are independent and additive, i.e. they appear to represent two quite different mechanisms of interference with growth (Lunn et al. 1997).

\section{Relationship between growth and mannitol uptake}

The low recovery of mannitol suggests reduced absorptive surface area, which in the small intestine can be equated with the partial villus atrophy seen in these infants on biopsy. In normal mucosa mature enterocytes line the surface of the villi and contain many of the enzymes required for digestion and absorption of nutrients, thus erosion of these cells will inevitably result in a decreased ability to absorb and digest foodstuffs. Although the availability of many enzymes may be reduced, perhaps the single most important one to consider in an infant consuming large amounts of breast milk is intestinal lactase. Lactose is the major carbohydrate of breast milk and accounts for approximately half its energy content. Breast feeding in The Gambia lasts for 21-24 months, and even at 12 months of age breast-milk lactose is estimated to provide 20-30 \% of the total energy intake of the average child (Prentice \& Paul, 1990). Clearly any substantial decrease in the ability to digest lactose could be expected to have significant consequences. Lactose digestion in the small intestine is dependent on the presence of lactase, an enzyme located in the brush border of mature enterocytes, but because of its exposed position on the villi, it is extremely vulnerable to pathogenic damage (Lebenthal, 1984). In addition, any lactose not hydrolysed in the small intestine would pass into the large bowel, and if the amount became substantial it could result in diarrhoea and other symptoms of lactose intolerance.

An estimate of lactase activity in these breast-feeding children was obtained by an extension of the intestinal permeability test, which utilized the fact that lactose and lactulose are isomers (Noone et al. 1986). In the normal gut almost all ingested lactose is quickly hydrolysed by small intestinal lactase, whereas lactulose is unaffected by this enzyme. Small amounts of both isomers are absorbed intact into the body and excreted into the urine in proportion to the amounts present in the small intestine. Thus lactose : lactulose, the fractional urinary excretion of the two isomers, gives an index of lactase activity, with a value of 1 indicating total alactasia. A ratio of 0.4 was taken as the upper limit in normolactasic individuals (Noone et al. 1986)

In Gambian infants total urinary lactose increased almost 3 -fold from 2 to 15 months of age, despite there being little change in breast-milk intake during this period (NorthropClewes et al. 1997). Likewise, there was a progressive increase in the lactase index (urinary lactose:lactulose) such that above 6 months of age mean values exceeded the upper limit of normal, indicating hypolactasia. At 12-15 months
$62 \%$ of individuals were judged to be hypolactasic and $26 \%$ were close to alactasia, with a ratio $>0.95$.

The lactase activity index was closely and inversely related to growth in both weight and length; the higher the index, the poorer the growth. However, a major part of this association overlapped with the intestinal permeabilitygrowth relationship, which indicates that much of the observed association between lactose maldigestion and length growth was part of the intestinal permeabilitygrowth relationship. However, a small but statistically significant part remained independent of intestinal permeability. Although there may be several possible explanations for this latter component, it may be connected with the rather early genetic loss of lactase that occurs in these children. Erinoso et al. (1992) reported a loss of lactase activity in most Gambian children by 3 years of age, which is much earlier than has been reported from other countries, and particularly in black Americans, many of whom originated from this part of Africa (Scrimshaw \& Murray, 1988).

Lactase is only one of the many enterocyte brush-border enzymes whose role is to digest and absorb nutrients. Its reduction in activity in line with mucosal damage, as indicated by the intestinal permeability test, particularly mannitol uptake, is likely to be reflected by reductions in many other similarly-sited enzymes.

\section{Relationship between growth and lactulose uptake}

The mucosa of the small intestine acts as an interface between the body and the environment, and under normal circumstances the barrier function of the organ prevents environmental pathogens, endotoxins and other macromolecules from entering the body. According to the permeability theory, increased lactulose uptake is an index of mucosal leakiness; i.e. it suggests that there has been a partial breakdown of the intestinal barrier function. Is there evidence to corroborate this conclusion?

Children living in developing countries have long been known to have higher than expected plasma concentrations of immunoglobulins ( $\operatorname{Ig}$ ), e.g. $\operatorname{IgA}, \operatorname{IgG}, \operatorname{IgM}$, and it is generally accepted to be a result of chronic stimulation of the immune system by a highly contaminated environment. Gambian infants develop this characteristic feature after 3-4 months of age, coincident with the onset of growth faltering, and by 9 months of age the mean concentrations of all three Ig were more than double the values for age-matched controls (Lunn et al. 1997). In addition, plasma concentrations of the acute-phase proteins, $\alpha 1$-antichymotrypsin and C-reactive protein, also became elevated beyond 3 months of age, as did plasma cortisol concentration (Lunn et al. 1979). These latter findings are also consistent with the infants having a chronic immune and inflammatory response to infection or damage in some part of their body. As may be expected under such conditions, growth performance was found to be reduced in relation to elevated levels of these plasma markers of disease.

However, raised concentrations of these plasma protein markers were also related to increased intestinal permeability, and particularly to a high level of lactulose uptake. The Venn diagram (Fig. 3) illustrates how plasma IgA 


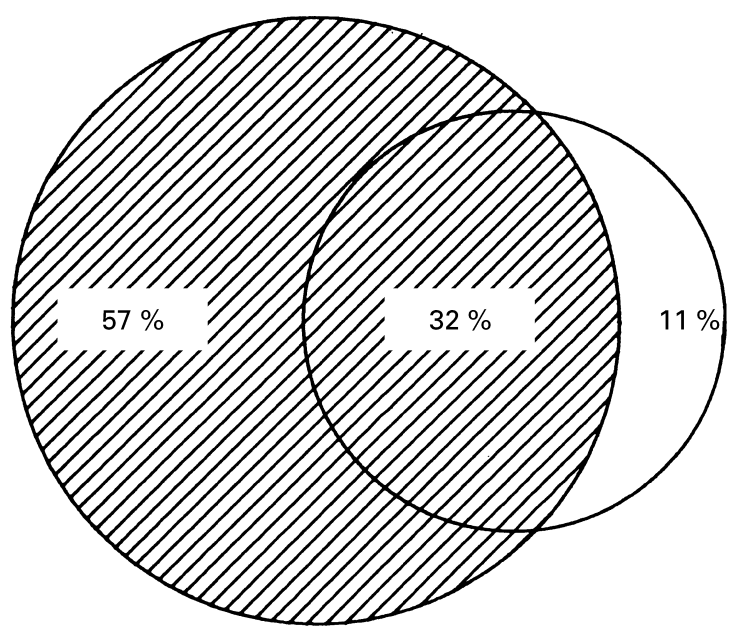

Ln L:M

Plasma $\lg \mathrm{A}$

Fig. 3. Venn diagram to illustrate the interrelationships between plasma immunoglobulin $(\mathrm{lg}) \mathrm{A}$ concentration $(O)$, intestinal permeability (lactulose : mannitol; L : M; $\bullet$ ) and growth in length. Percentage values within the diagram show the relative contribution of each sector to the total $r^{2}$ value $(0 \cdot 49)$. Data were calculated by regression analysis.

concentration interrelates with intestinal permeability, and their association with length growth. The overall $r^{2}$ for the association with growth was $0 \cdot 49$, but $76 \%$ of the $\operatorname{IgA}$ relationship was coincident with the permeability association, suggesting that the two variables are part of the same growth-restricting mechanism. Interrelationships between the other plasma markers and intestinal permeability with growth in either length or weight gave similar results.

These results are consistent with an increased leakiness of the mucosal barrier function that allows increased translocation of macromolecules such as endotoxins, food proteins and perhaps whole organisms through the mucosa and into the body where they stimulate both local and systemic inflammatory and immune mechanisms. As the overlap between permeability and $\mathrm{Ig}$ associations with growth is so large, it seems that the damaged small intestinal mucosa represents the major point of entry of environmental hazards into the body of these Gambian infants.

More direct evidence is provided by measurement of IgG anti-endotoxin antibodies in the plasma. Titres were found to be within the normal range at 2-3 months of age, but quickly increase with age such that by 7 months they are about 3-fold greater than expected. Gram-negative bacteria in the gut are the most likely source of endotoxin, and the association of high endotoxin antibodies with abnormal intestinal permeability confirms that translocation does occur in these children.

The overall picture obtained is that a raised intestinal permeability is associated with poor growth and with raised systemic inflammatory and immune reaction. Reduced mannitol uptake, suggesting reduced absorptive surface area, is associated with reduced lactase activity, and probably with other types of maldigestion and/or malabsorption. The raised lactulose uptake is indicative of increased intestinal barrier function leakiness, which appears to allow increased translocation of macromolecules, i.e. food proteins, endotoxins and perhaps even whole bacteria through the intestinal wall and into the body, where both local and systemic immune and inflammatory mechanisms are stimulated. Both mechanisms can be expected to result in poor growth.

\section{Nature of the mucosal enteropathy}

The work described so far has centred around the use of the intestinal permeability test as an indication of small intestinal disease, but what is the situation in the gut which gives rise to the raised permeability values? Although it would be unethical to biopsy the small intestinal mucosa of apparently-healthy village infants, biopsies have been obtained from severely-malnourished children admitted to hospital. Mucosal biopsies have now been obtained from more than 100 children and all have shown partial to subtotal villus atrophy, moderate to severe crypt hyperplasia and marked infiltration of intra-epithelial lymphocytes (Sullivan et al. 1991). The lamina propria was also congested with inflammatory cells. The overall appearance was, in general, similar to that seen in coeliac disease or cow's-milk-protein enteropathy. T-cell subpopulations (CD3, CD4 and CD8) were 2-3-fold higher than those of UK controls, but the CD8:CD4 value was normal. Cells expressing the CD25 activation marker were seen, on average, thirteen times more frequently than in UK controls and $\gamma \delta$-T-cells were elevated to a level seen in coeliac disease. Many of the intra-epithelial lymphocytes contained perforin granules that indicate cytotoxic capability, a finding which indicates that the mucosa is under severe distress, with effete cells being destroyed (Campbell et al. 1999c). These findings confirm that the enteropathy occurs as a result of a cell-mediated inflammatory reaction in the mucosa leading to increased rates of cell destruction.

The need for an increased rate of enterocyte production to counter this effect would account for the observed increase in crypt size; however, the rate of cell production assessed by mitotic activity was found to be low. This result is surprising because the same crypt cells have a much increased frequency of expression of the $\mathrm{Ki}^{+} 7^{+}$marker, which identifies cells preparing for division. The finding suggests that although the signal for cell division is present, some other factor is preventing completion of the process (Campbell et al. 1999a). These abnormalities were seen in all children investigated, and their severity was independent of nutritional indices such as weight, length and BMI Z-scores.

Another finding requiring more investigation is a shift in balance of the number of T-cells producing pro- (tumour necrosis factor $\alpha$ and interferon- $\gamma$ ) and anti-inflammatory (interleukein 10 and transforming growth factor $\beta$ ) cytokines with increasing severity of malnutrition. Although both pro- and anti-inflammatory cytokine-producing cell numbers were elevated in all these children, the rise was smaller the more malnourished they were. Moreover, in these more malnourished children the numbers of cells producing anti-inflammatory cytokines were more markedly reduced, leaving pro-inflammatory cytokine-producing cells predominant (Campbell et al. 1999b). Whether this process occurs as a progressive shift with increasing malnutrition or 
whether it reflects a differing genetic make-up which predisposes to more severe illness has not yet been defined.

\section{Causes and aetiology of enteropathy}

There seems little doubt that the unhygienic circumstances in which these children live must contribute to, if not be the overriding cause of, the enteropathy. However, despite several investigations no specific mechanism or organism has been unequivocally identified as a major cause of the enteropathy or of the associated growth faltering. Nevertheless, two organisms deserve further mention. Helicobacter pylori infection is very common in The Gambia and, by its effect on lowering stomach acidity, may allow other pathogens easier access to the small intestine (Dale et al. 1998). Infants infected with $H$. pylori from an early age do grow rather less well than those infants that remain uninfected throughout the first year of life, but both groups still show the same pattern of growth faltering. Giardia intestinalis is also extremely common, and infants are exposed to this parasite at a very early age. By 3 months of age $45 \%$ of children show a positive IgM titre to this parasite, and by 6 months of age more than $80 \%$ have been exposed. An acute elevation of Giardia-specific IgM is associated with a raised intestinal permeability, raised acutephase proteins and reduced weight gain, but when assessed over a 6-month period, these relationships failed to reach significance (Lunn at al. 1998).

Both these organisms are transmitted by ingestion of faecally-contaminated material, and the observation that at least some infants have already been exposed by the age of 2 months demonstrates not only the high endemicity of the organisms in this area, but also the poor level of hygiene. It may be that the observed associations with growth were simply a reflection of the level of faecal ingestion rather than a specific effect of either $H$. pylori or Giardia. Moreover, the sporadic apparent disappearance and reappearance of these pathogens during the first year of life suggests that faecal contamination continues throughout this time. It may be that the enteropathy arises and is maintained by frequent exposure to a combination of these and other faecally-derived organisms. Other possible initiation factors include food toxins, e.g. aflatoxin, which can be a problem in The Gambia (Wild et al. 1992), or much less likely, a so far unidentified nutrient deficiency.

Once established the enteropathy persists for many months, and even when children are hospitalized regeneration of a normal mucosal structure is extremely slow (Sullivan et al. 1992). The reason for this slow recovery is far from clear, but may be connected with the very low mitotic index and regeneration of crypt cells. The refractory nature of the lesion could also be due to a vicious circle whereby the translocation of antigenic molecules through the damaged mucosa initiate further immune and inflammatory processes which potentiate the injury. Repair mechanisms may also be compromised by a nutrient supply that is inadequate for efficient tissue repair. Alternatively, continued ingestion of organisms or toxins may prevent recovery, as would a persistent low-level pathogen infection. Equally baffling is why some children show sudden marked improvement after many months of enteropathy. Has there been a sudden improvement in hygiene or nutrient supply, or has it occurred as a result of treatment given for some other illness? There is clearly scope for further investigations here.

\section{Intestinal permeability throughout life in The Gambia}

The data described so far has been collected from children in the first 2 years of life, and shows a gradual deterioration until 12-15 months. Child growth in this region of The Gambia remains slow, however, and there is little catch-up until the pubertal spurt; so does small bowel mucosal illness persist throughout childhood? To answer this question, a cross-sectional study of how intestinal permeability changed with age was performed in 150 subjects equally divided across six age-groups, i.e. 2-5, 5-10, 10-15, 15-20, 20-30 and $>30$ years (PG Lunn and D Campbell, unpublished results). Two measurements were taken, one in the dry season and the second 6 months later during the rains.

The results showed that intestinal permeability values improved with age but never achieved UK values. The reason for this situation was that mannitol recovery remained constant throughout all ages at about $5 \%$, i.e. somewhere between half to one-third of the UK range of 11-15 \%. This finding suggests that the mucosal architecture remains abnormal throughout life. However, because of the overcapacity of the small bowel mucosa for digestion and absorption, this loss of absorptive capacity may have little impact once growth has ceased. On the other hand, lactulose uptake improved throughout childhood and reached UK values between the ages of 10 and 15 years. This result indicates that although it improves with age, increased mucosal leakiness persists throughout childhood, and the resulting inflammatory and immune responses may explain the failure of catch-up growth before puberty.

This study also produced several relationships that suggest that intestinal permeability values of individuals may have become 'set' at an early age and persist throughout life. First, there was a relationship between intestinal permeability and season of birth; irrespective of age, subjects born during the first 3 months of the year had a more normal mucosa than those born in the third quarter (lactulose:mannitol were 0.160 (SD 0.098) and 0.249 (SD 0.090) respectively; $P<0.001$ ). Moreover, height-forage $\mathrm{Z}$-scores showed a similar effect, those born in the first quarter of the year were taller than those born in the third quarter. Second, across all ages, and after correcting for age and sex, there was a relationship $\left(r^{2} 0 \cdot 12, P<0 \cdot 01\right)$ between intestinal permeability and attained height (assessed as height-for-age Z-score), although not with weight. Finally, although nearly all intestinal permeability values were abnormally high, there was a strong association between the first and second measurements within individuals. For lactulose:mannitol, $r^{2} 0.44$ and for lactulose uptake $r^{2} 0.29$ (both $P<0.001)$; mannitol recovery was less-closely related, $r^{2} 0.05(P<0 \cdot 05)$.

Although other interpretations are possible, these results are certainly in keeping with the hypothesis that intestinal permeability becomes 'set' in some way at an early stage and that this affects the individual throughout life. The finding of Moore et al. (1997) that the age of death in these 
same Gambian villagers varies with month of birth could, at least partly, be explained on this basis. The 'good' and 'bad' months to be born for longevity correspond to the good and bad months of birth for intestinal permeability. Is it possible that a persistent small bowel inflammatory enteropathy, associated with constant stimulation of the immune system, compromise the ability of the immune system to respond efficiently to other immune challenges, and thus increase deaths from infective diseases?

\section{Summary}

The overall picture is illustrated in Fig. 4. Pathogenic organisms and/or food allergens ingested with food, water or from contaminated hands or feeding utensils cause the initial damage to the mucosa of the small intestine. There are then at least two ways in which the injured mucosa is associated with growth faltering. First, partial villus atrophy results in a loss of enzymes that are required for the normal digestion and absorption of food. Second, the mucosal damage compromises the barrier function of the small intestine, allowing the translocation of antigenic macromolecules into both the mucosal tissues and to the blood. The translocated material stimulates immune and inflammatory responses, both locally and systemically, with the local inflammation causing further damage to the intestinal mucosa.

Despite the severity of the mucosal damage and inflammation, the illness appears to be essentially asymptomatic apart from the growth faltering. Although these infants do suffer with diarrhoea for about $7-10 \%$ of the time and often lose weight during acute episodes, they tend to catch up after each episode so that their overall growth between 2 and 15 months does not relate to diarrhoea prevalence. Perhaps more surprising is that although intestinal permeability tends to be elevated during acute diarrhoea, when viewed over this same period no long-term relationship between these variables can be observed. The lack of symptoms probably explains why this serious condition has not been previously identified as a major cause of infant growth faltering in developing countries. In The Gambia every infant studied (over 400)

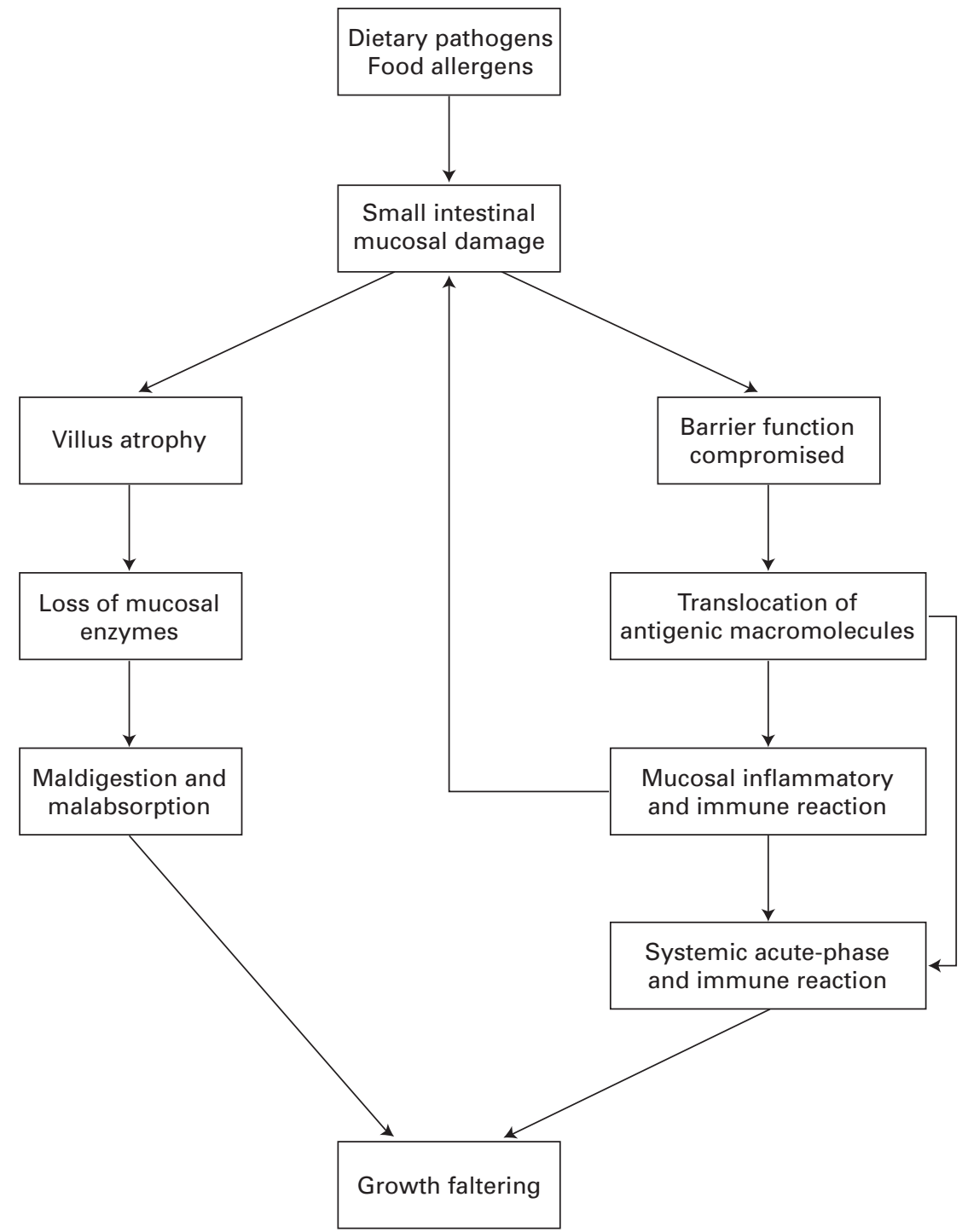

Fig. 4. Diagrammatic representation of the mechanisms leading to poor growth in Gambian children. 
has suffered from mucosal enteropathy to a greater or lesser extent at some time during the first 15 months of life.

Since our first description of the condition in apparentlyhealthy village infants (Lunn et al. 1991a,b), there have been reports of its existence throughout the developing world, from Asia (Roy et al. 1992; Raj et al. 1996), Africa (Brasseur et al. 1992; Brewster et al. 1997), South America (Fagundes et al. 1994) and Australasia (Kukuruzovik et al. 1999), thus it seems likely that it will be found wherever infant growth faltering occurs. An 'enteropathy of malnutrition' has been described in severely-malnourished children for many years, but has always been thought of as a consequence of the malnutrition and not as a cause. Our data suggest that the enteropathy seen in severe cases is simply a progression of the damage that had existed for long periods in apparently- 'healthy' children, and that it is more likely to be the cause of the malnutrition rather than the result.

Neither supplementary feeding nor vitamin and mineral supplementation have improved the growth performance of Gambian infants, nor have they had any impact on intestinal permeability. It seems likely, therefore, that the failure of so many dietary intervention schemes to improve nutritional status throughout the developing world may be explained by the unsuspected presence of a mucosal enteropathy in the small bowel. The full impact of this mucosal damage on infant and child growth cannot be properly established until effective treatment or preventative measures can be found. Until then, intervention schemes aimed at improving the nutritional status of infants and young children in developing countries should consider the probable existence of a mucosal enteropathy and its effect on growth.

\section{References}

Brasseur D, Goyens P \& Vis HL (1992) Enzymes et histologie de la muquese intestinale de nourrissons Africains allaites (Enzymes and histology of the intestinal mucosa of breast-fed African infants). Annales de Pediatrie 39, 87-93.

Brewster DR, Manary MJ, Menzies IS, O’Loughlin EV \& Henry RL (1997) Intestinal permeability in kwashiorkor. Archives of Diseases in Childhood 76, 242-248.

Briend A, Hasan KZ, Aziz KMA \& Hoque BA (1989) Are diarrhoea control programmes likely to reduce childhood malnutrition? Observations from rural Bangladesh. Lancet ii, 319-322.

Campbell DI, Murch SH, Lunn PG, Elia M, Sullivan PB \& Jobarteh $\mathrm{B}(1999 a)$ Imbalance between $\mathrm{T}_{\mathrm{H}} 1$ and T-regulatory cytokines in enteropathy of malnutrition. Journal of Pediatric Gastroenterology and Nutrition (In the Press).

Campbell DI, Murch SH, Lunn PG, Elia M, Sullivan PB \& Mendy J (1999b) Disruption of the epithelial mitotic cycle in tropical enteropathy and malnutrition. Journal of Pediatric Gastroenterology and Nutrition (In the Press).

Campbell DI, Murch SH, Sullivan PB, Elia M \& Lunn PG (1999c) Inflammatory cell populations in mucosal enteropathy of malnourished Gambian children: relationships with small intestinal permeability. Journal of Pediatric Gastroenterology and Nutrition (In the Press).

Cole TJ \& Parkin JM (1977) Infection and its effect on the growth of young children. Transactions of the Royal Society of Tropical Medicine and Hygiene 76, 196-198.

Dale A, Thomas JE, Darboe MK, Coward WA, Harding M \& Weaver LT (1998) Helicobacter pylori infection, gastric acid secretion and infant growth. Journal of Pediatric Gastroenterology and Nutrition 26, 393-397.

Elia M, Behrens R, Northrop C, Wraight P \& Neale G (1987) Evaluation of mannitol, lactulose and $51 \mathrm{Cr}$-labelled ethylenediamine-tetra-acetate as markers of intestinal permeability in man. Clinical Science 73, 197-204.

Erinoso HO, Hoare S, Spencer S, Lunn PG \& Weaver LT (1992) Is cow's milk suitable for the dietary supplementation of rural Gambian children? Prevalence of lactose maldigestion. Annals of Tropical Paediatrics 12, 359-365.

Fagundes NU, Martins MC, Lima FL, Patricio FR \& Toledo MR (1994) Asymptomatic environmental enteropathy among slumdwelling infants. Journal of the American College of Nutrition 13, 51-56.

Ford RPK, Menzies IS, Philips AD, Walker-Smith JA \& Turner NW (1985) Intestinal sugar permeability: relationship to diarrhoeal disease and small bowel morphology. Journal of Pediatric Gastroenterology and Nutrition 4, 568-574.

Hamill PVV, Drizd TA, Johnson CL, Reed R, Roche AF \& Moore WM (1979) Physical growth: National Center for Health Statistics percentiles. American Journal of Clinical Nutrition 32, 607-696.

Kukuruzovic RH, Haase A, Dunn K, Bright A \& Brewster DR (1999) Intestinal permeability and diarrhoeal disease in aboriginal Australians. Archives of Disease in Childhood (In the Press).

Lebenthal E (editor) (1984) Prolonged small intestinal mucosal injury as a primary cause of intractable diarrhoea of infancy. In Chronic Diarrhoea in Children. Nestle Nutrition Workshop Series, vol. 6, pp. 31-56. New York: Raven Press.

Lunn PG, Whitehead RG, Cole TJ \& Austin S (1979) The relationship between hormonal balance and growth in children and rats. British Journal of Nutrition 41, 73-84.

Lunn PG, Northrop-Clewes CA \& Downes RM (1991a) Intestinal permeability, mucosal injury and growth faltering in Gambian infants. Lancet 338, 907-910.

Lunn PG, Northrop-Clewes CA \& Downes RM (1991b) Chronic diarrhoea and malnutrition in The Gambia: studies on intestinal permeability. Transactions of the Royal Society of Tropical Medicine and Hygiene 85, 8-11.

Lunn PG, Northrop-Clewes CA \& Downes RM (1993) Long-term growth faltering in Gambian infants is related to intestinal damage but not diarrhoeal prevalence. Transactions of the Royal Society of Tropical Medicine and Hygiene 87, 371.

Lunn PG, Northrop-Clewes CA \& Downes RM (1997) Growth in rural Gambian infants is closely related to small-intestinal permeability: Why? Proceedings of the Nutrition Society 56, 280A.

Lunn PG, Erinoso HO, Northrop-Clewes CA \& Boyce SA (1998) Giardia intestinalis is unlikely to be a major cause of the poor growth of rural Gambian infants. Journal of Nutrition 129, $872-877$.

Menzies IS (1984) Absorption of intact oligosaccharides in health and disease. Biochemical Society Transactions 2, 1042-1046.

Moore SE, Cole TJ, Poskitt EME, Sonko BJ, Whitehead RG, McGregor IA \& Prentice AM (1997) Season of birth predicts mortality in rural Gambia. Nature 338, 434.

Noone C, Menzies IS, Banatvala JE \& Scopes JW (1986) Intestinal permeability and lactose hydrolysis in human rotaviral gastroenteritis assessed simultaneously by non-invasive sugar permeation. European Journal of Clinical Investigation 16, $217-225$.

Northrop-Clewes CA, Lunn PG \& Downes RM (1997) Lactose maldigestion in breast-feeding Gambian infants. Journal of Pediatric Gastroenterology and Nutrition 24, 257-263.

Prentice A (1993) Nutrient requirements for growth, pregnancy and lactation: The Keneba experience. South African Journal of Clinical Nutrition 6, 33-38. 
Prentice A \& Paul AA (1990) Contribution of breast milk to nutrition during prolonged breast-feeding. In Human Lactation. 4. Breast-feeding, Nutrition, Infection and Infant Growth in Developed and Emerging Countries, pp. 88-101 [S Atkinson, L Hanson and R Chandra, editors]. St Johns, Nfld.: ARTS Biomedical Publishers.

Raj SM, Sein KT, Anuar AK \& Mustaffa BE (1996) Effects of intestinal helminthiasis on intestinal permeability of early primary schoolchildren. Transactions of the Royal Society of Tropical Medicine and Hygiene 90, 666-669.

Roy SK, Behrens RH, Haider R, Akramuzzaman SM, Mahalanabis D, Wahed MA \& Tomkins AM (1992) Impact of zinc supplementation on intestinal permeability in Bangladeshi children with acute diarrhoea and persistent diarrhoea syndrome. Journal of Pediatric Gastroenterology and Nutrition 15, 289-296.
Scrimshaw NS \& Murray EB (1988) Prevalence of lactose maldigestion. American Journal of Clinical Nutrition 48, 1086-1098. Sullivan PB, Lunn PG, Northrop-Clewes CA, Crowe PT, Marsh MN \& Neale G (1992) Persistent diarrhoea and malnutrition - the impact of treatment on small bowel structure and permeability. Journal of Pediatric Gastroenterology and Nutrition 14, 208-215.

Sullivan PB, Marsh MN, Mirakian R, Hill SM, Milla PJ \& Neale G (1991) Chronic diarrhoea and malnutrition - histology of the small intestinal mucosal lesion. Journal of Pediatric Gastroenterology and Nutrition 12, 195-203.

Wild CP, Hudson GJ, Sabbioni G, Chapot B, Hall AJ, Wogan GN, Whittle H, Montesano R \& Groopman JD (1992) Dietary intake of aflatoxins and the level of albumin-bound aflatoxin in peripheral blood in The Gaxmbia, West Africa. Cancer Epidemiology, Biomarkers and Prevention 1, 229-234. 